\title{
Induction of Oral Tolerance in Neonatal Mice by Transfer of Food Allergens as IgA-Immune Complexes in Breast Milk
}

\author{
Kumiko Kizu' ${ }^{1}$, Ayu Matsunaga ${ }^{2}$, Junko Hirose ${ }^{3}$, Akihiro Kimura4, Hiroshi Narita ${ }^{2}$ \\ ${ }^{1}$ Department of Life and Living, Osaka Seikei College, Osaka, Japan \\ ${ }^{2}$ Department of Food and Nutrition, Kyoto Women's University, Kyoto, Japan \\ ${ }^{3}$ Department of Food Science and Nutrition, School of Human Cultures, The University of Shiga Prefecture, \\ Hikone, Japan \\ ${ }^{4}$ Itayado Clinic, Kobe, Japan \\ Email: narita@kyoto-wu.ac.jp
}

Received 16 January 2015; accepted 3 February 2015; published 11 February 2015

Copyright (C) 2015 by authors and Scientific Research Publishing Inc.

This work is licensed under the Creative Commons Attribution International License (CC BY).

http://creativecommons.org/licenses/by/4.0/

(c) (i) Open Access

\begin{abstract}
Various opinions have been presented on the merits and demerits that breastfeeding gives for the allergic onset of the babies. In this report, we focused on whether food proteins eaten by mother mice and secreted into breast milk as IgA-immune complexes contribute to the allergy prevention through oral tolerance in infants who ingest the milk. BALB/c mice were divided into two groups; E-group fed only egg white proteins and M-group fed only cow's milk proteins as a dietary protein source. After immunizing M-group infants fed their own mother's milk with ovalbumin/alum, diarrhea associated with experimental Th2 intestinal inflammation was induced by oral administration of ovalbumin. The diarrhea was dramatically suppressed in E-group infants. Concomitantly, low level of serum anti-ovalbumin- and ovomucoid-IgG1 and IgE, suppression of IL-4 synthesis by spleen cells, and low incidence of anaphylactic death after intravenous injection of ovalbumin were observed preferentially in E-infants. Immune complexes of respective dietary proteins and IgA were found in the breast milk obtained from each group of mother. Oral administration of pseudo immune complex chemically synthesized with ovalbumin and monoclonal mouse IgA in advance effectively suppressed anti-ovalbumin-IgG1 synthesis in adult mice after immunization with ovalbumin. The tolerance induced by the pseudo immune complex of ovalbumin diminished spontaneously while mice did not take egg white proteins. Thus, immune tolerance and then prevention of allergic disorder against dietary proteins were acquired via breastfeeding by mothers feeding the relevant proteins, probably through the immune complexes of dietary proteins and sIgAs secreted into breast milk.
\end{abstract}


Keywords

\section{Breastfeeding, Oral Immune Tolerance, Food Allergy, IgA, Immune Complex}

\section{Introduction}

Breastfeeding is just the fundamental biological behavior for mammals. Therefore, breast milk is reasonably considered to be the most appropriate food for infants providing nutritional, developmental, psychological, social, economical, and environmental benefits [1]. In addition, there are extensive observations supporting another key role of breastfeeding in protecting infants from infectious diseases [2] [3]. The protection mainly relies on the passive immunity due to the transfer of large amount of microbe-specific IgA acquired from breast milk to compensate for the reduction of immunoglobulin from umbilical cord blood and the deficiency of its self-synthesis during the first year of life [4]. IgA also functions as a protective factor against allergic diseases, as expected from inverse relationship between IgA production and incidence of allergy [5] [6]. It interrupts the penetration of antigens (microbes and food proteins) from the surface of intestinal mucosal membrane. However, conflicting results have been proposed epidemiologically about the influence of breastfeeding on the allergic responsiveness in progeny [7]-[10]. Variations in many factors such as genetics, kinds of allergens and allergies, routes and timing of allergen exposure, and maturation of mucosal immunity may affect on the allergic risks in progeny. Even under the appropriate experimental conditions in mice, breast milk may be protective [11] or susceptible [12] to the development of allergic asthma in progeny.

Food proteins eaten by mothers are known to be secreted into breast milk at ng $\mu \mathrm{g} / \mathrm{ml}$. Concerning food allergy, whether they are promotive (sensitization) or suppressive (tolerance) against food allergy is the critical matter for infants [13]. Mother's oral allergen avoidance is successfully introduced as the cure for food allergy of infants, especially for atopic dermatitis. However, it has recently proved that the effect might be due to the block not of oral exposure but of cutaneous one [14]. In addition, since rigorous dietary egg exclusion could not eliminate trans-placental and trans-breast milk egg allergen passage, maternal preventive dietary restriction has been thought to be fruitless exercise [7] [15], so is not recommended now in the world [16]. Then, why breast milk contains allergens? Are those nothing more than leak or do they have an unknown physiological function? We have revealed occurrence of the major food allergen, ovomucoid, in human breast milk as an immune complex (IC) with specific IgA [17]. IgA-IC is reported to be effectively internalized by M cell, a specialized epithelial cell located on Peyer's patch in intestine, through its specific IgA receptor [18], delivering antigens to intraepithelial and subepithelial dendritic cells and lymphocytes for subsequent IgA production [19]. Then, we have expected some positive function in allergy prevention from IgA-IC in breast milk.

In this report, we describe the evidence indicating that food proteins eaten by mothers and secreted into breast milk as IgA-IC contribute to the allergy prevention through oral tolerance in infants who ingest the milk. Preliminary results suggesting induction of oral tolerance through breastfeeding were obtained also in rats [20]. If tolerance can be induced in infants by breastfeeding with usual maternal eating habit without any special medical treatment, it becomes possible to give a new and great breakthrough to the prevention and therapy against allergic diseases and then to the promotion of breastfeeding itself.

\section{Materials and Methods}

\subsection{Materials}

Ovomucoid (OM) was purified from egg white [21]. Egg white protein or soy protein was a gift from Q.P. Corporation (Ibaraki, Japan) or Fuji Oil Co., LTD. (Osaka, Japan) and used after supplementation with $0.00125 \%$ of biotin or $0.46 \%$ of methionine, respectively. The following materials were obtained from the sources indicated: plates for enzyme linked immunosorbent assays (ELISAs) (MaxiSorp; Nunc, Roskilde, Denmark); PD-10 column (GE Healthcare, Buckinghamshire, UK); Imject Alum Adjuvant, mouse IL-4 ELISA Kit, Sulfosuccinimidyl 6-[3'-(2-pyridyldithio)-propionamido]hexanoate (Sulfo-LC-SPDP), and Protein G and L agarose (Thermo Fisher, Rockford, USA); Mouse/Rat/Porcine/Canine TGF- $\beta 1$ Immunoassay (R\&D Systems Inc., Minneapolis, USA); Freund's complete and incomplete adjuvants (Difco, MI, USA); BSA, Ovalbumin (OVA; grade V), red blood cell lysing buffer and oxytocin (Sigma-Aldrich, St. Louis, USA); OVA-free bovine milk whey proteins 
(Morinaga Milk Industry Co., LTD., Kanagawa, Japan). All other chemicals used were of the highest purity available.

\subsection{Mice}

Female BALB/c mice (8 weeks old) were obtained from Japan SLC (Shizuoka, Japan) and fed commercially available mouse diet and water ad libitum. At the start of experiments (10 - 12 weeks old), diet was changed to the AIN-93G based purified diet, in which protein was replaced with OVA-free bovine milk whey proteins (M-mice) or egg white proteins (E-mice). M- and E-mice were bred in each group and pups were breastfed by relevant mothers (M- and E-pups). To prevent pups from eating mother's diets and feces after 10 days of age, mothers and pups were housed separately and breastfeeding was done only in pup's cages at night. After weaning at 21 days, both pups were fed with the purified diet, in which protein was replaced with soy proteins. All experiments were approved by the Animal Experiment Committee of Kyoto Women’s University.

\subsection{OVA-Induced Diarrhea}

E- and M-pups were sensitized twice, 2 weeks apart, with $20 \mu \mathrm{g}$ of OVA in the presence of $1 \mathrm{mg}$ of alum by intraperitoneal (i.p.) injection. Two weeks later, they were orally administered $200 \mu \mathrm{l}$ of sterile saline containing $20 \mathrm{mg}$ of OVA with intragastric feeding needles 8 times for every 2 - 3 days. Before each intragastric challenge, mice were deprived of food for 3 - 4 hours. Diarrhea was assessed by visual monitoring of mice for up to one hour following intragastric challenge. Mice demonstrating profuse liquid stool were recorded as diarrhea-positive animals.

\subsection{Systemic Anaphylaxis and Cytokine Determination}

One day after the final diarrhea experiment, systemic anaphylaxis was induced to a part of mice by intravenous injection of $40 \mu \mathrm{g}$ of OVA in $50 \mu \mathrm{l}$ of PBS $(0.15 \mathrm{M} \mathrm{NaCl}$ in $10 \mathrm{mM} \mathrm{NaPi}$ buffer, $\mathrm{pH}$ 7.4). The number of mice died within an hour was counted. Spleens were removed from the rest of the mice and $2 \times 10^{6}$ spleen cells treated with red blood cell lysing buffer (Sigma) were cultured in triplicate for $72 \mathrm{~h}$ with or without $10 \mu \mathrm{g}$ of OVA in RPMI 1640 medium containing 10\% fetal calf serum. Concentrations of IL-4 and TGF- $\beta 1$ in the culture medium were determined by the commercial ELISA kits according to the manufacturer's recommendations.

\subsection{Mouse Serum and Milk}

Blood samples obtained from mice were centrifuged at $3000 \times \mathrm{g}$ for $5 \mathrm{~min}$ at $4^{\circ} \mathrm{C}$ to remove particulate materials. Sera were subdivided into sterile containers, and stored at $-20^{\circ} \mathrm{C}$ until use. Repetitive freeze and thaw was avoided.

Milk samples were collected from mother mice on days 14 after delivery. They were separated from pups for $16 \mathrm{~h}$ before milking. To facilitate the collection, a single injection of one IU of oxytocin was given subcutaneously 5 min before milking. Between $100-500 \mu \mathrm{l}$ of milk were collected from each mother, with a milking apparatus for experimental animals (WAT-2001, Little Leonardo, Japan) and were centrifuged at 10,000 $\times \mathrm{g}$ for 10 min at $4^{\circ} \mathrm{C}$ after adding equal volume of PBS. The top lipid layer and the bottom precipitate were discarded and the clear whey was subdivided into sterile containers and stored at $-20^{\circ} \mathrm{C}$ until use. Repetitive freeze and thaw was avoided.

\subsection{Specific IgG1 and IgE in Sera}

OVA- or OM-specific IgG1 in sera was determined by respective ELISA. Briefly, ELISA plate was coated with $50 \mu \mathrm{l}$ of $2 \mu \mathrm{g} / \mathrm{ml}$ each antigen, blocked with $200 \mu \mathrm{l}$ of $1 \%$ BSA in PBS, and incubated with serial dilutions of serum samples followed by Alkaline phosphatase (ALP)-conjugated anti-mouse IgG1 (BETHYL, Montgomery, USA). At each step, wells were washed well with a washing buffer $(0.1 \%$ BSA, $0.05 \%$ Tween-20, and $0.15 \mathrm{M}$ $\mathrm{NaCl}$ in $10 \mathrm{mM}$ Tris-HCl Buffer, $\mathrm{pH}$ 7.4). Finally, $100 \mu \mathrm{lof} 1 \mathrm{mg} / \mathrm{ml} \rho$-nitrophenyl phosphate was added. ALP reaction was carried out at $37^{\circ} \mathrm{C}$ and was monitored with absorbance at $405 \mathrm{~nm}$ using a microplate reader (BioRad, Munich, Germany). The standard curve was drawn on the same plate for test samples. Wells were first coated with $50 \mu \mathrm{l}$ of $5 \mu \mathrm{g} / \mathrm{ml}$ anti-mouse IgG1 (BETHYL), blocked with $200 \mu \mathrm{l}$ of 1\% BSA in PBS, and incubated with serial dilutions of the standard mouse IgG1 (Southern Biotech, Birmingham, USA) followed by ALP- 
conjugated anti-mouse IgG1.

After removal of excess amount of serum IgG with Protein G agarose (Thermo), OVA-specific IgE was measured as like as OVA-specific IgG1 by using horse radish peroxidase (HRP)-conjugated anti-mouse IgE (Binding Site, Birmingham, UK) and tetramethylbenzidine. The standard curve was drawn with anti-mouse IgE (CALTAG, Burlingame, USA) and mouse IgE (Southern Biotech). Enzymatic reaction was carried out at $37^{\circ} \mathrm{C}$ and monitored with absorbance at $450 \mathrm{~nm}$ after stopping with sulfuric acid.

\subsection{IgA- or IgG-Immune Complex in Breast Milk}

Immune complex of OVA was determined with sandwich ELISAs constructed with anti-OVA and anti-IgA or IgG. ELISA plates were coated with $50 \mu \mathrm{l}$ of $5 \mu \mathrm{g} / \mathrm{ml}$ of anti-OVA (CAPPEL/ICN MP Biomedicals, OH, USA), blocked with $200 \mu \mathrm{l}$ of $1 \%$ BSA in PBS, and incubated with serial dilutions of mouse breast milk followed by ALP-conjugated anti-mouse IgA ( $\alpha$ ) (BETHYL) or anti-mouse IgG (American Qualex). The standard curve was drawn with anti-mouse IgA or IgG as the solid antibody and mouse IgA or IgG as a standard. ALP reaction was carried out as stated above. Immune complex of OM was measured as like as that of OVA with plates coated with anti-OM (Morinaga Institute of Biological Science Inc., Yokohama, Japan).

\subsection{Preparation of Pseudo-Immune Complex and Its Administration}

A monoclonal IgA producing cell was established according to the methods described previously by the fusion of myeloma P3U1 cells and mesentery lymph node cells obtained from a BALB/c mouse fed with egg protein diet [21]. The light chain of the monoclonal IgA was $\kappa$, then it was purified by Protein L column from serum free-culture media of the hybridoma. The antigen specificity of the IgA could not be identified, but it did not react with major food proteins in chicken egg white and cow's milk. The IgA showed a broad peak around 200 $400 \mathrm{kDa}$ on a gel-filtration analysis, and molecular weight of its heavy chain was estimated to be about $60 \mathrm{kDa}$ on reduced SDS-PAGE, suggesting dimer formation (data not shown) [19].

OVA was coupled to the purified IgA with SPDP according to the manufacturer's procedure. To $3.5 \mathrm{mg}$ of OVA dissolved in $1 \mathrm{ml}$ of PBS containing $1 \mathrm{mM}$ EDTA, $42 \mu \mathrm{l}$ of $20 \mathrm{mM}$ SPDP was added and kept for $30 \mathrm{~min}$ at room temperature. After removal of free SPDP with PD-10 column, $2.0 \mathrm{mg}$ of the IgA was added to the solution and incubated overnight at room temperature. The resulting solution was applied to a Protein $\mathrm{L}$ agarose column. More than $80 \%$ of OVA added were collected in through fraction and the bound proteins were eluted with $0.1 \mathrm{M}$ Glycine-HCl buffer $\mathrm{pH} 3.0$ and immediately neutralized with $0.1 \mathrm{M}$ Tris-HCl buffer $\mathrm{pH}$ 9.6. After dialysis against PBS, the bound fraction was designated as OVA-pseudo IC, which was confirmed and determined by the ELISA used for OVA-IC in breast milk. Therefore, its amount was expressed as IgA unit. One ng of OVApseudo IC as IgA was considered to contain no more than $1.75 \mathrm{ng}$ of free OVA, providing all of OVA added was coupled to IgA and recovered in the OVA-pseudo IC fraction during its preparation.

Varying amounts of OVA-pseudo IC were administered orally for successive 6 days to 8 weeks old BALB/C mice fed casein-based commercially available mouse diet. At day 7, they were immunized with $50 \mu \mathrm{g}$ of egg white proteins with Freund's complete adjuvant and boosted twice at day 21 and 49 with $50 \mu \mathrm{g}$ of egg white proteins with Freund's incomplete adjuvant. Blood was drawn from orbital vein at day 35 and by cardiac puncture at day 63 and serum OVA- and OM-specific IgG1s were measured.

\subsection{Statistical Analysis}

The statistical difference was determined by two-sided Student's $t$ test, Welch's $t$ test, or Mann-Whitney's $U$ test depending on the distribution pattern of the data. Difference with $p<0.05$ was considered significant.

\section{Results}

\subsection{Induction of Oral Tolerance in Infants by Maternal Dietary Proteins}

In order to reveal the effects of maternal dietary proteins on the development of food allergy in their progeny, $\mathrm{BALB} / \mathrm{c}$ mice were allocated into two groups; E-mice fed only egg white proteins and M-mice fed only cow's milk proteins as a dietary protein source. Pups born from and breastfed by E-mothers are referred as "E-pups" and those born from and breastfed by M-mothers as "M-pups" hereafter. They were carefully raised as exclusive 
breastfed animals for 21 days as stated in Materials and Methods. When infants were immunized twice with OVA by using Freund's adjuvants after weaning and their serum OVA-specific IgG1 levels were measured, dramatic reduction was observed in E-pups compared to M-pups (Figure 1). It was dose-dependent; the higher the content of egg white proteins in maternal diet, the lower the serum OVA-specific IgG1 levels in infants. When E-100 pups were immunized with casein, they showed strong IgG1 production against casein (data not shown), indicating that their IgG producing ability itself was normal and suppression was specific to the maternal dietary proteins. When alum was used as an adjuvant, serum OVA-specific IgE was not enough to be measured at this age (7 weeks old). We used Freund's adjuvants here because they are known to elicit IgG response stronger than alum and the level of IgG1 changes parallel to that of IgE.

\subsection{Protection of Oral Allergen-Induced Diarrhea in Infants by Maternal Dietary Proteins}

To assess the application of this result for the prevention of food allergy, we introduced a murine model of oral allergen-induced intestinal inflammation accompanied by strong local and systemic Th2 responses [22]. In this model, antigen-specific and dose-dependent acute diarrhea can be introduced by repeated doses of intragastric OVA after intraperitoneal sensitization of BALB/c mice with OVA/alum (Figure 2(a)). When M-pups were applied to the protocol, they developed acute diarrhea about 15 - 30 minutes after the third oral OVA challenge (Figure 2(b)). In contrast, E-pups were resistant to the oral OVA challenges. Diarrhea was also confirmed by direct observation of the colon and cecum that the liquid stool was seen in M-pups contrasted with the solid pellets in E-pups (Figure 2(c)). Loss of Body weight was seen in M-pups before and after the oral OVA challenges (Figure 2(d)). Furthermore, when lethal anaphylactic shock was induced by the intravenous injection of OVA to the pups after oral OVA challenges, five of six died in M-pups but only one of nine in E-pups within an hour. Figure 2(e) showed the survival curve drawn according to the method of Kaplan-Meier. There was statistically significant difference between both groups $(p<0.01)$ [23]. Collectively in other words, neonates can acquire oral tolerance against maternal dietary proteins through breast feeding, suggesting that breast milk act as a natural drinkable vaccine against food allergy in neonates.

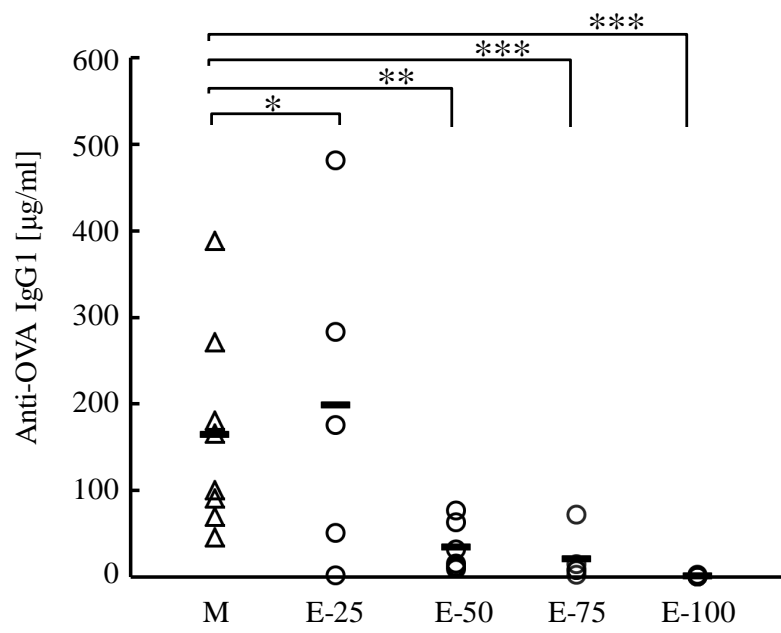

Figure 1. Dose-dependent reduction of serum OVA-specific IgG1 in infants by maternal dietary egg white proteins. Female BALB/c mice (10 weeks old) were fed with the diets containing cow's milk proteins and egg white proteins at different ratios (M: $100 \%$ milk proteins, E-25, $-50,-75$, $-100: 25 \%, 50 \%, 75 \%, 100 \%$ egg white proteins compensated with milk proteins, respectively). Pups born from and breastfed by each mother were immunized intraperitoneally by $10 \mu \mathrm{g}$ of OVA with Freund's complete adjuvant at weaning and boosted two weeks later by the same amount of OVA with Freund's incomplete adjuvant. Their blood samples were drawn two weeks later and the serum OVA-specific IgG1 levels were measured. Individual results were presented in five groups of 8 pups for M, 5 for E25, 6 for E-50, 5 for E-75, and 8 for E-100. Crossbars are the mean values. ${ }^{*} p>0.05,{ }^{* *} p<0.05,{ }^{* * *} p<0.01$ compared to M-pups. 


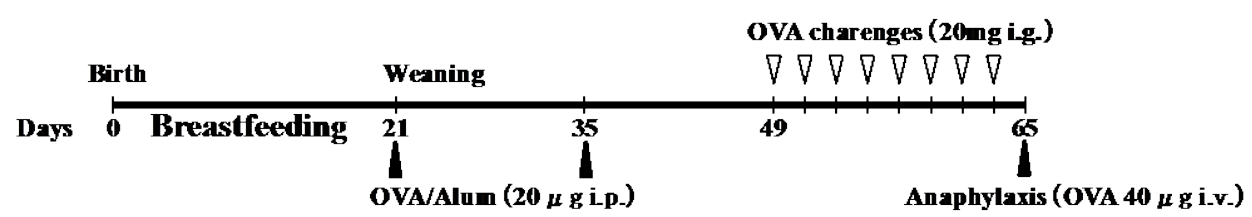

(a)

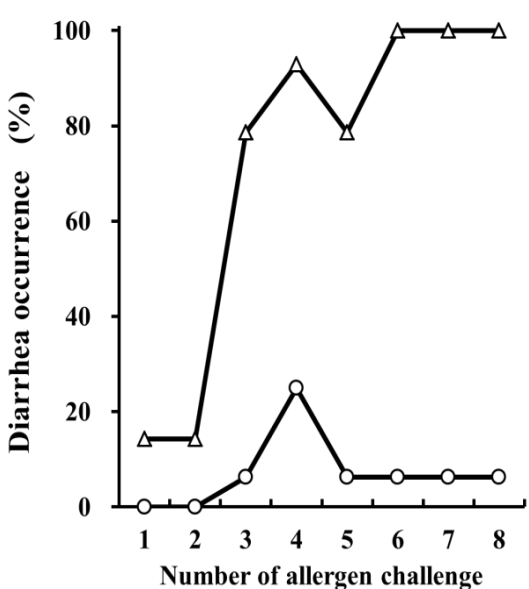

(b)

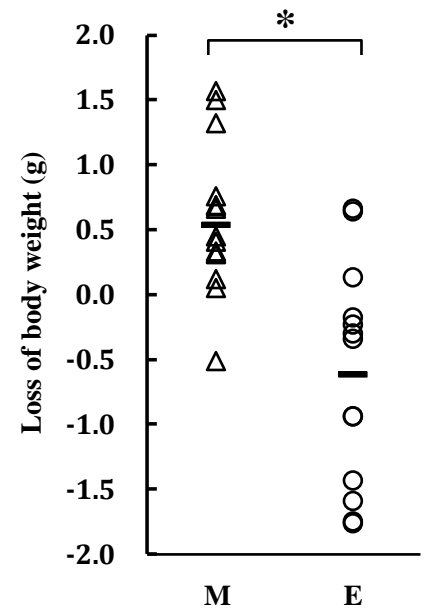

(d)
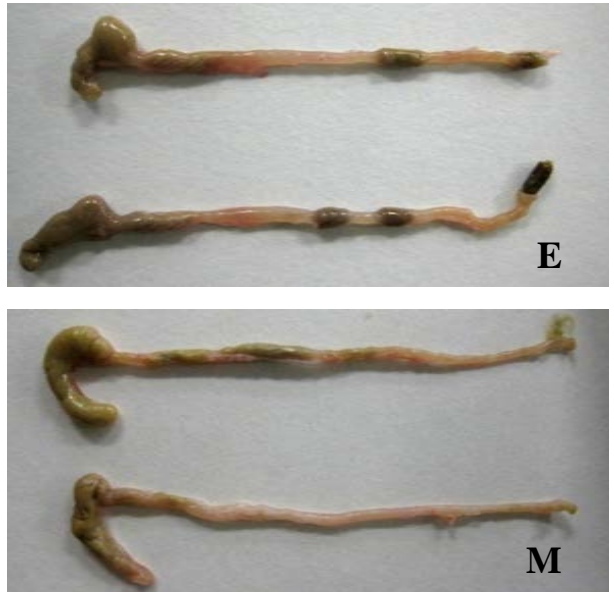

(c)

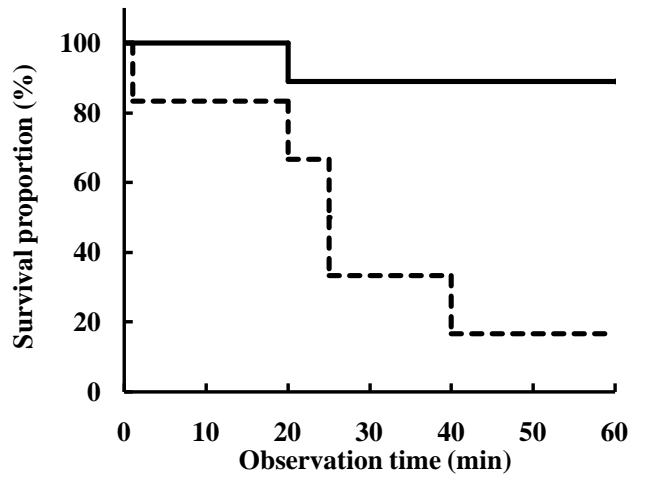

(e)

Figure 2. Oral OVA-induced diarrhea in infants breastfed by mother mice fed with egg white proteins. (a) Schematic representation of the experimental schedule. Female BALB/c mice were fed only with cow's milk proteins (M-mice) or egg white proteins (E-mice) as a dietary protein source. Pups born from and breastfed by E-mothers (E-pups: $n=16,4$ males and 12 females) and those by M-mothers (M-pups: $n=14,7$ males and 7 females) were intraperitoneally (i.p.) immunized twice, 2 weeks apart, with $20 \mu \mathrm{g}$ of OVA in alum after weaning and subsequently treated with intragastric (i.g.) OVA challenges (20 mg each) 8 times for every 2-3 days; (b) Diarrhea occurrence in E-pups (circles) and M-pups (triangles) was assessed 15 - 60 minutes after each intragastric OVA challenge; (c) Representative photographs of the cecum and colon extirpated from E-pups (upper) or M-pups (lower) 60 minutes after 8 intragastric OVA challenges; (d) Loss of body weights before and after 8 intragastric OVA challenges in individual E-pups (circles) and M-pups (triangles). Crossbars are the mean values. ${ }^{*} p<0.01$ between both groups; (e) Systemic anaphylaxis was induced in E-pups (solid line, $n=9$ ) and M-pups (broken line, $n=6$ ) by intravenous injection (i.v.) of $40 \mu \mathrm{g}$ of OVA after 8 intragastric OVA challenges. Survival curve was drawn according to the method of Kaplan-Meier and the log-rank test was used to compare two groups of survival times [23]. 


\subsection{Antibody and Cytokine Responses in Infants}

OVA-induced diarrhea seen above is known to be associated with other immunological manifestations of allergy, such as antibody production and cytokine profile. OVA/alum immunization of the E-pups after weaning resulted in markedly reduced serum levels of OVA-specific IgG1 as compared to M-pups before and during diarrhea induction (Figure 3(a)). Although serum OVA-specific IgE was not enough to measure before diarrhea induction, significantly lower levels were determined in E-pups than in M-pups after diarrhea induction (Figure 3(b)). It resulted in the high incidence of anaphylactic death only in M-pups (Figure 2(e)). The mouse showed the highest serum IgE level in E-pups was the only one died in E-pups by anaphylactic shock. To assess the cytokine profile regulated by $\mathrm{T}$ cells, spleen cells of infants after diarrhea induction were isolated and cultured in vitro in the presence or the absence of OVA. TGF- $\beta$ is the representative cytokine known to be suppressive against IgE production and IL-4 is the one known to be promotive. While OVA-dependent production of TGF- $\beta$ by spleen cells was slightly higher in E-pups than in M-pups $(p=0.09$ ) (Figure 3(c)), that of IL-4 was greatly inhibited in E-pups ( $p=0.04$ ) (Figure 3(d)), consistent with the lower level of serum IgE in E-pups (Figure 3(b)) and suggesting the suppression of Th2 response by breastfeeding.

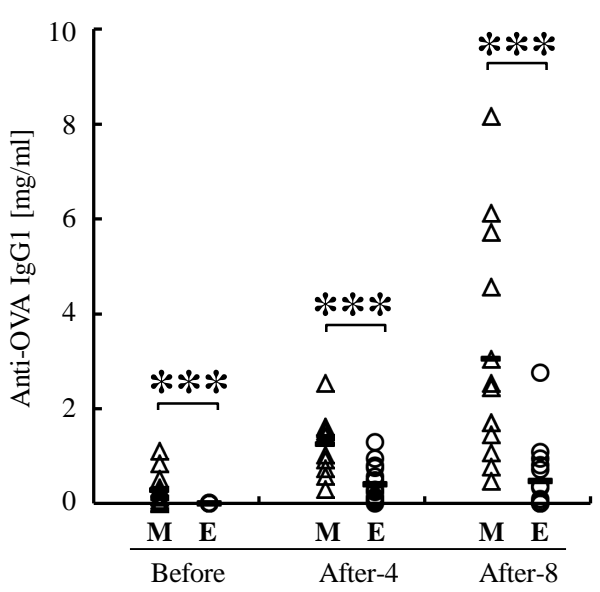

(a)

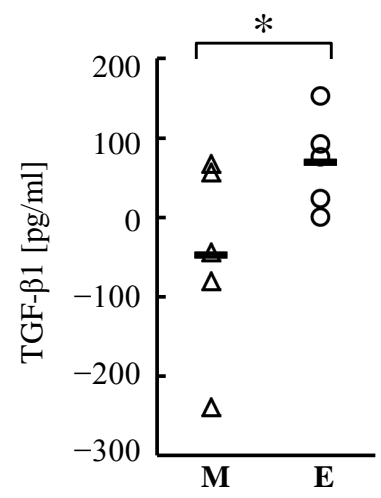

(c)

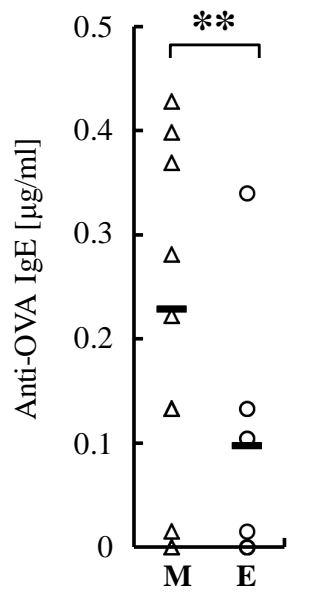

(b)

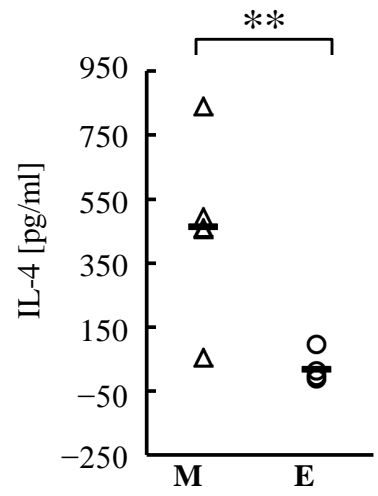

(d)

Figure 3. Association of oral OVA-induced diarrhea with antibody and cytokine responses in infants. Before intragastric OVA challenges (Before) and after 4 and 8 times challenges (After-4 and -8) in Figure 2(a), blood was drawn from orbital vein and OVA-specific IgG1 (a) and IgE (b) were measured in individual E-pups (circles, $n=16$ ) and M-pups (triangles, $n=14$ ). OVA-dependent secretion of TGF- $\beta 1$ (c) and IL-4 (d) were analyzed with spleen cells obtained from 5 mice of each group after 8 times challenges. Differences of the values obtained with or without OVA were expressed. Crossbars are the mean values. ${ }^{*} p>0.05$, ${ }^{* *} p<0.05,{ }^{* * *} p<0.01$ between both groups. 


\subsection{Maternal Factors in Breast Milk Influencing to Immune System of Progeny}

Preliminary experiments showed that the dietary proteins of fathers and mothers before pregnancy did not relate to the results obtained in Figure 1 (data not shown). Therefore, the development of progeny's immune system is influenced predominantly by the maternal factors that could be transferred from the mother to the progeny in utero and/or after birth (i.e. through breastfeeding). To elucidate the contribution of breastfeeding on the protective effects seen above, we had changed the diet of M-mother to that of egg white proteins only during pregnancy (EM-mother) or breastfeeding (ME-mother). The marked decrease of serum OVA-specific IgG1 levels was also observed in EM- and ME-pups by the immunization with egg white proteins/alum after weaning as like as in E-pups (Figure 4(a)). Ovomucoid (OM), another major allergen in egg white [21], exhibited stronger antigenecity to IgG production than OVA (Figure 4(a) and Figure 4(b)). OM-specific IgG1 levels were concomitantly reduced in EM- and ME-pups compared to M-pups (Figure 4(b)). It is certainly notable that the sufficient immune tolerance against food proteins could be acquired in ME-pups breastfed by mothers who ate the egg white proteins only during breastfeeding, indicating the predominant importance of some factor secreted into breast milk. Decrease of OVA- and OM-specific IgG1 production in EM-pups might be therefore explained by formation of the factor during pregnancy and secreted into breast milk late after delivery.

Because immunological responses including oral tolerance seen above are the events specific to antigens, something specific to maternal food protein such as protein itself, specific antibody, and/or specific lymphocyte in breast milk is the candidate for the factor transferred from mother to progeny. According to our finding that OM is present in human breast milk as an immune complex (IC) with OM-specific secretory IgA [17], IgA-ICs for OVA and OM were determined in breast milk of mice by specific ELISAs. As expected, both IgA-ICs were detected specifically only in the milk samples obtained from E-mothers (Figure 5(a) and Figure 5(b)). While OM exhibited over 10-fold stronger antigenecity to mucosal IgA production than OVA did as like as to IgG production (Figure 4 and Figure 5), neither IgG-IC was detected in the breast milk of mice (data not shown). IgA-IC was confirmed to be more plausible factor for the induction of oral tolerance than IgG-IC in normal breast milk of mice.

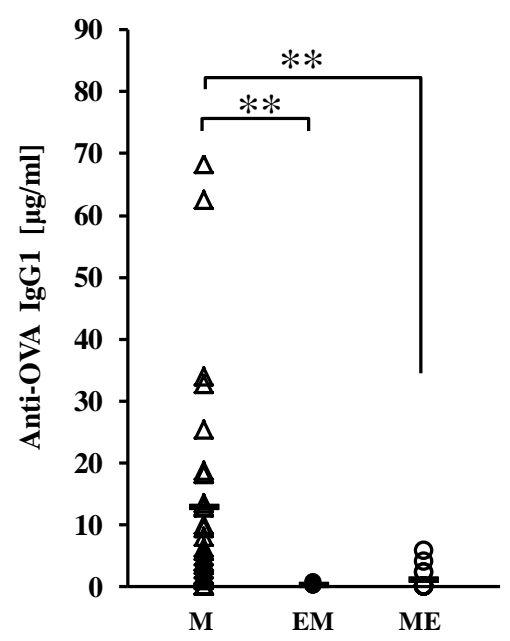

(a)

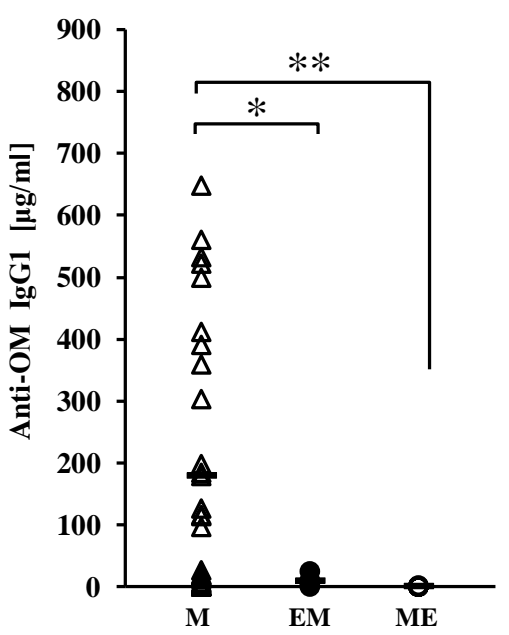

(b)

Figure 4. Effect of maternal dietary egg white proteins before and after delivery on serum OVA-specific IgG1 in infants. Female BALB/c mice (12 weeks old) were fed with the diet containing cow's milk proteins throughout the experiment (M-mother). The diet of M-mother was changed to that of egg white proteins only during pregnancy (EM-mother) or lactation (ME-mother). Pups born from and breastfed by each mother were intraperitoneally (i.p.) immunized twice, 2 weeks apart, with $10 \mu \mathrm{g}$ of egg white proteins in alum after weaning. Their blood samples were drawn two weeks later and the serum OVAspecific (a) and OM-specific (b) IgG1 levels were measured. Individual results were presented in three groups of 30 mice for M, 4 for EM, and 15 for ME. Crossbars are the mean values. ${ }^{*} p>0.05,{ }^{* *} p<0.01$ compared to M-mice. 


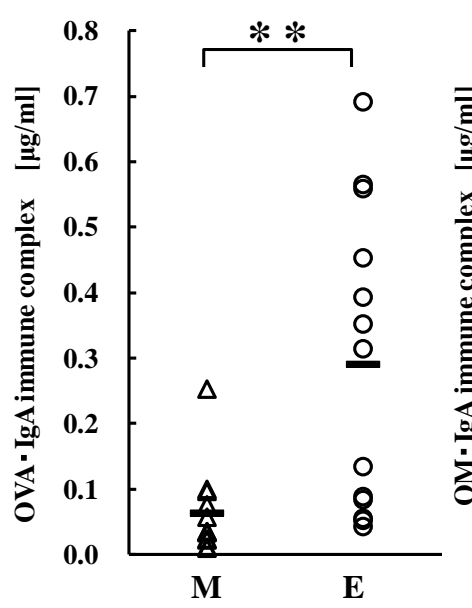

(a)

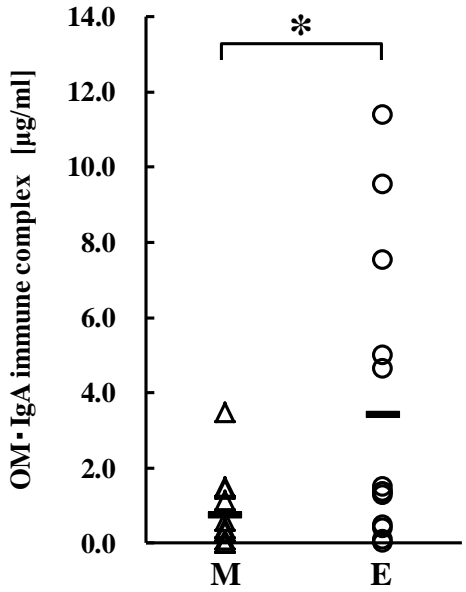

(b)

Figure 5. IgA-immune complexes for OVA and OM in mouse breast milk. IgA-immune complexes for OVA (a) and OM (b) in mouse breast milk were measured with specific ELISAs. Results were presented as $\mu \mathrm{g}$ of IgA $/ \mathrm{ml}$ in individual E-milk (circles, $\mathrm{n}=13$ ) and M-milk (triangles, $\mathrm{n}$ $=12$ ). Crossbars are the mean values. ${ }^{*} p<0.05,{ }^{* *} p<0.01$ between both groups.

\subsection{Suppression of Serum OVA-Specific IgG1 Production by Oral Administration of Pseudo-Immune Complex Chemically Synthesized with OVA and Mouse Monoclonal IgA}

To clarify the direct effect of IgA-IC in breast milk towards the induction of oral tolerance in infants, a mass preparation of mouse IgA was necessary. Then, we established an IgA producing hybridoma and got a large amount of homogeneous IgA. OVA was coupled to the monoclonal IgA with hetero-bifunctional crosslinking reagent, SPDP, to make OVA-pseudo IC (see Materials and Methods). Its formation was confirmed by the sandwich ELISA with anti-OVA antibody and ALP-conjugated anti-mouse IgA ( $\alpha$ ) antibody (data not shown).

When OVA-pseudo IC was orally administered to mice fed casein-based commercial diet, dose dependent suppression of serum OVA-specific IgG1 production was observed after the first boost of egg white proteins (Figure 6(a)). The maximum dose of OVA-pseudo IC (500 ng/day) was selected based on the concentration of OVA-IC in breast milk (Figure 5(a)) and a volume of milk ingested in a day as one ml. Because precise molecular feature of OVA-pseudo IC was unknown, the amount of free OVA (875 ng) in the control experiment was the estimated maximum value calculated from the maximum dose of OVA-pseudo IC. Probably, it was about ten times more than the real amount of bound OVA and could induce tolerance slightly. The suppression was specific to the protein coupled to IgA because OM-specific IgG1 production after the first boost of egg white proteins was unchanged by OVA-pseudo IC administration (Figure 6(b)). However, the suppression observed in OVA-IgG1 production after the first boost was not seen after the second boost, indicating that the tolerance induced by pseudo IC was reversible and canceled during three weeks between two boosts (Figure 6(c)).

\section{Discussion}

Dietary proteins that escaped from luminal digestion subsequently contact with the epithelium, under which mucosal immune system lies, to generate a wide range of immunological responses. After uptake and processing of antigens by an array of different types of cells in mucosal immune system, secretory IgA is synthesized and secreted as an exclusion antibody and IgE production is suppressed to induce oral tolerance, specifically to the antigens. It is postulated that depression or breakdown of this system results in food allergy [24] and that its immaturity is one of the reasons for the prevalence of food allergy in neonates and involvement of breast milk, especially allergens in it is the other. We have revealed in this paper, however, that oral immune tolerance against maternal dietary proteins is acquired in neonatal mice by breastfeeding and incidence of allergic disorder such as allergen-induced diarrhea is suppressed (Figures 1-3). It was the event taken place during lactation by 


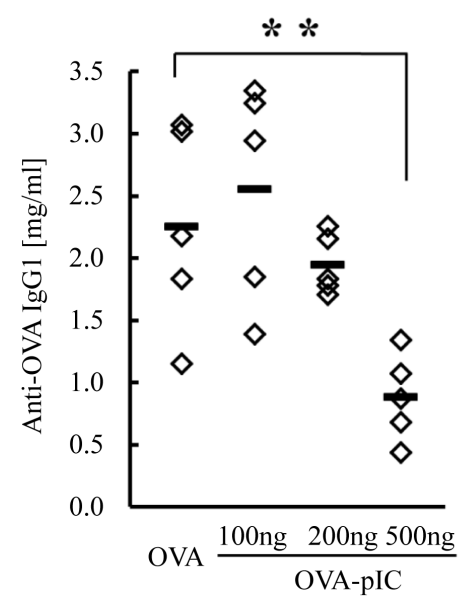

(a)

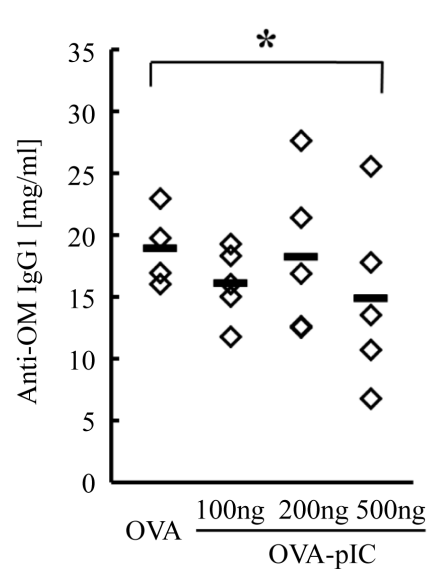

(b)

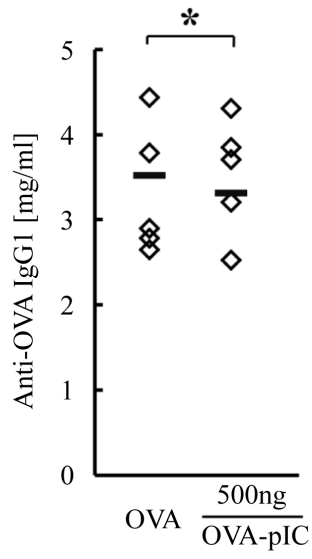

(c)

Figure 6. Reversible suppression of serum OVA-specific IgG1 production by oral administration of pseudo-immune complex. OVA-pseudo IC $(100,200$, or $500 \mathrm{ng}$ as IgA unit) was administered orally to 8 weeks old BALB/c mice fed casein-based diet for successive 6 days. Free OVA (875 ng) was administered as the control. At day 7, they were immunized with $50 \mu \mathrm{g}$ of egg white proteins with Freund's complete adjuvant and boosted twice at day 21 and 49 with $50 \mu$ g of egg white proteins with Freund's incomplete adjuvant. Blood was drawn from orbital vein at day 35 and by cardiac puncture at day 63 and serum OVA- and OM-specific IgG1s were measured. (a) OVA; (b) OM specific IgG1 after the first boost; and (c) OVA-specific IgG1 after the second boost. Crossbar is the mean of each group of 5 mice. ${ }^{*} p>0.05,{ }^{* *} p<0.05$ compared to the control.

breastfeeding, because sufficient tolerance against egg proteins was induced even when the mother ate them only during lactation (Figure 4). Suppression of IgG1 production against OVA or casein in infants was also observed in rats when E- or M-pups were immunized with egg white or milk whey proteins respectively [20]. Therefore, induction of tolerance by breastfeeding in infants is supposed to occur in general beyond the kind of proteins, foods, and animals, and was too natural to be noticed in human so far. Then, we propose a hypothesis here that breast milk acts as a natural drinkable vaccine against food allergy in neonates.

Significantly high level of TGF- $\beta$ in human milk [25] and its possible function in oral tolerance are reported [11] [26]. Because tolerance is the event specific to antigen, involvement of antigen is essential in tolerance induction. TGF- $\beta$ in breast milk, therefore, might act as a potentiator. Then, some common components present both in mother's diet and in breast milk are thought to be the factor inducing the tolerance. We have previously revealed occurrence of OM as IgA-IC in human and rat breast milk [17] [20] and found OVA and OM IgA-IC in breast milk this time from mouse mother fed with egg white proteins (Figure 5). Recently, IgA-IC has been reported to work as the transporter of antigens through specific IgA receptor and promotes subsequent IgA production and maturation of mucosal immune system [18] [19] [27]. Furthermore, it was also found that the antigen binding to secretory IgA results in decreased sensitivity to intestinal proteases and increased binding to cellular Fc receptors [28], implying the physiological importance of IgA-IC formation. These findings indicated that IgA-IC in breast milk is the most plausible candidate for the inducer of the tolerance in neonates. To obtain the direct evidence to prove the function, we prepared OVA IgA-IC artificially, named pseudo IC and showed suppression of serum OVA IgG1 synthesis by the oral administration of OVA pseudo IC to mice in advance (Figure 6(a) and Figure 6(b)). Now we have confirmed the occurrence of food proteins as IgA-IC in human, rat and mouse breast milk, depending on dietary history, amount of intake, condition and constitution of individual mother. It will be necessary hereafter to investigate the relationship between IgA-IC in breast milk and clinical manifestations of infants ingested it.

Three kinds of mechanism were proposed for the induction of oral immune tolerance [24]. Lymphocyte anergy and clonal deletion are induced with high doses of oral antigen. Anergy can occur through T cell receptor cross-linking in the absence of co-stimulatory signals. Clonal deletion occurs by means of FAS-mediated apoptosis. Low doses of oral antigen favor tolerance driven by regulatory $\mathrm{T}$ cells, which suppress immune responses through soluble or cell-surface associated suppressive cytokines such as TGF- $\beta$. The mechanism for the toler- 
ance induced by breastfeeding in this study may be the active suppression of Th2 response by regulatory $\mathrm{T}$ cells due to the low concentration of IgA-IC in breast milk. In fact, tolerance induced by breastfeeding in rats [20] and by pseudo IC in mice in this paper (Figure 6(c)) was canceled while animals did not take the relevant antigens by themselves. In general, there are many cases reported that start of weaning is postponed or particular protein or food is removed from baby food for fear of allergic sensitization, preventively without doctoral direction. It seems necessary to start weaning while tolerance acquired by breastfeeding is effective [29]. Thus, breastfeeding should be accomplished after having understood its potential physiological significance well.

In contrast to IgA, existence of a neonatal IgG Fc receptor-dependent shuttle was reported, by which IgG once secreted out from epithelial cells into intestine formed IgG-IC with antigen there and returned inside again to stimulate mucosal immune system [30]. Involvement of this pathway has been noticed lately in the induction of oral tolerance by breastfeeding in neonates and prevention of asthma development [31] [32]. However, neither OVA nor OM IgG-IC was detected in our mouse milk samples (data not shown), probably due to the suppression of IgG synthesis in mother mice by the diet-induced oral tolerance. Furthermore in the IgG system, mother mice were made allergic by intraperitoneal antigen sensitization and then exposed to antigen aerosols during lactation to increase IgG-IC in breast milk. Although breast milk even from allergic mothers may protect offspring from allergic airway inflammation in mice, such a treatment is not applicable to human therapy. Our system is just eating in contrast. We have revealed a new insight here that tolerance could be acquired in infants potentially by breastfeeding dependent on the natural maternal eating habit without any special medical treatment.

Recently, sublingual immunotherapy (SLIT) or specific oral tolerance induction (SOTI) is noticed and introduced clinically [33]. After knowing the physiological importance of IgA-IC in breast milk, application of natural and pseudo IC to these new therapies is hopeful. Breast milk is the only food originally present for infants of individual mammals and also is the natural drinkable vaccine against food proteins that infants will encounter near future. We hope this work provides a chance to reassess the power of breastfeeding by standing on the origin of mammals.

\section{Acknowledgements}

This work was supported in part by grants from Japan Society for the Promotion of Science and The Kieikai Research Foundation.

\section{References}

[1] Gartner, L.M., Morton, J., Lawrence, R.A., Naylor, A.J., O’Hare, D., Schanler, R.J. and Eidelman, A.I. (2005) Breastfeeding and the Use of Human Milk. Pediatrics, 115, 496-506. http://dx.doi.org/10.1542/peds.2004-2491

[2] Labbok, M.H., Clark, D. and Goldman, A.S. (2004) Breastfeeding: Maintaining an Irreplaceable Immunological Resource. Nature Reviews Immunology, 4, 565-572. http://dx.doi.org/10.1038/nri1393

[3] Ip, S., Chung, M., Raman, G., Chew, P., Magula, N., DeVine, D., Trikalinos, T. and Lau, J. (2007) Breastfeeding and Maternal and Infant Health Outcomes in Developed Countries. Evidence Report-Technology Assessment, 153, 1-186. http://archive.ahrq.gov/downloads/pub/evidence/pdf/brfout/brfout.pdf

[4] Brandtzaeg, P. (2003) Mucosal Immunity: Integration between Mother and the Breast-Fed Infant. Vaccine, 21, 33823388. 10.1016/S0264-410X(03)00338-4

[5] Geller-Bernstein, C., Weissglas, L., Dun, R., Tsur, S., Kahane, P. and Lahav, M. (1980) Immunoglobulin E and A Levels in Atopic and Anaphylactic Children. Annals of Allergy, 44, 29-33.

[6] Aghamohammadi, A., Cheraghi, T., Gharagozlou, M., Movahedi, M., Rezaei, N., Yeganeh, M., Parvaneh, N., Abolhassani, H., Pourpak, Z. and Moin, M. (2009) IgA Deficiency: Correlation between Clinical and Immunological Phenotypes. Journal of Clinical Immunology, 29, 130-136. http://dx.doi.org/10.1007/s10875-008-9229-9

[7] Kramer, M.S. and Kakuma, R. (2014) Maternal Dietary Antigen Avoidance during Pregnancy or Lactation, or Both, for Preventing or Treating Atopic Disease in the Child. Evidence-Based Child Health, 9, 447-483. http://dx.doi.org/10.1002/ebch.1972

[8] Ehlayel, M.S. and Bener, A. (2008) Duration of Breast-Feeding and the Risk of Childhood Allergic Diseases in a Developing Country. Allergy and Asthma Proceedings, 29, 386-391. http://dx.doi.org/10.2500/aap.2008.29.3138

[9] Sicherer, S.H., Wood, R.A., Stablein, D., Lindblad, R., Burks, A.W., Liu, A.H., Jones, S.M., Fleischer, D.M., Leung, D.Y. and Sampson, H.A. (2010) Maternal Consumption of Peanut during Pregnancy Is Associated with Peanut Sensi- 
tization in Atopic Infants. Journal of Allergy and Clinical Immunology, 126, 1191-1197.

http://dx.doi.org/10.1016/j.jaci.2010.08.036

[10] Duncan, J.M. and Sears, M.R. (2008) Breastfeeding and Allergies: Time for a Change in Paradigm? Current Opinion in Allergy and Clinical Immunology, 8, 398-405. http://dx.doi.org/10.1097/ACI.0b013e32830d82ed

[11] Verhasselt, V., Milcent, V., Cazareth, J., Kanda, A., Fleury, S., Dombrowicz, D., Glaichenhaus, N. and Julia, V. (2008) Breast Milk-Mediated Transfer of an Antigen Induces Tolerance and Protection from Allergic Asthma. Nature Medicine, 14, 170-175. http://dx.doi.org/10.1038/nm1718

[12] Leme, A.S., Hubeau, C., Xiang, Y., Goldman, A., Hamada, K., Suzaki, Y. and Kobzik, L. (2006) Role of Breast Milk in a Mouse Model of Maternal Transmission of Asthma Susceptibility. Journal of Immunology, 176, 762-769. http://dx.doi.org/10.4049/jimmunol.176.2.762

[13] Strobel, S. (2001) Immunity Induced after a Feed of Antigen during Early Life: Oral Tolerance v. Sensitisation. Proceedings of the Nutrition Society, 60, 437-442. http://dx.doi.org/10.1079/PNS2001119

[14] Lack, G. (2008) Epidemiologic Risks for Food Allergy. Journal of Allergy and Clinical Immunology, 121, $1331-1336$. http://dx.doi.org/10.1016/j.jaci.2008.04.032

[15] Vance, G.H., Lewis, S.A., Grimshaw, K.E., Wood, P.J., Briggs, R.A., Thornton, C.A. and Warner, J.O. (2005) Exposure of the Fetus and Infant to Hens’ Egg Ovalbumin via the Placenta and Breast Milk in Relation to Maternal Intake of Dietary Egg. Clinical \& Experimental Allergy, 35, 1318-1326. http://dx.doi.org/10.1111/j.1365-2222.2005.02346.x

[16] Greer, F.R., Sicherer, S.H. and Burks, A.W. (2008) Effects of Early Nutritional Interventions on the Development of Atopic Disease in Infants and Children: The Role of Maternal Dietary Restriction, Breastfeeding, Timing of Introduction of Complementary Foods, and Hydrolyzed Formulas. Pediatrics, 121, 183-191. http://dx.doi.org/10.1542/peds.2007-3022

[17] Hirose, J., Ito, S., Hirata, N., Kido, S., Kitabatake, N. and Narita, H. (2001) Occurrence of the Major Food Allergen, Ovomucoid, in Human Breast Milk as an Immune Complex. Bioscience, Biotechnology, and Biochemistry, 65, 14381440. http://dx.doi.org/10.1271/bbb.65.1438

[18] Mantis, N.J., Cheung, M.C., Chintalacharuvu, K.R., Rey, J., Corthésy, B. and Neutra, M.R. (2002) Selective Adherence of IgA to Murine Peyer's Patch M Cells: Evidence for a Novel IgA Receptor. Journal of Immunology, 169, 1844-1851. http://dx.doi.org/10.4049/jimmunol.169.4.1844

[19] Weltzin, R., Lucia-Jandris, P., Michetti, P., Fields, B.N., Kraehenbuhl, J.P. and Neutra, M.R. (1989) Binding and Transepithelial Transport of Immunoglobulins by Intestinal M Cells: Demonstration Using Monoclonal IgA Antibodies against Enteric Viral Proteins. Journal of Cell Biology, 108, 1673-1685. http://dx.doi.org/10.1083/jcb.108.5.1673

[20] Kizu, K., Hirose, J., Honjo, T. and Narita, H. (2012) Induction of Oral Immune Tolerance through Breast-Feeding in Rats. Japan Society of Nutrition and Food Science, 64, 13-19. http://dx.doi.org/10.4327/jsnfs.65.13

[21] Hirose, J., Kitabatake, N., Kimura, A. and Narita, H. (2004) Recognition of Native and/or Thermally Induced Denatured Forms of the Major Food Allergen, Ovomucoid, by Human IgE and Mouse Monoclonal IgG Antibodies. Bioscience, Biotechnology, and Biochemistry, 68, 2490-2497. http://dx.doi.org/10.1271/bbb.68.2490

[22] Brandt, E.B., Strait, R.T., Hershko, D., Wang, Q., Muntel, E.E., Scribner, T.A., Zimmermann, N., Finkelman, F.D. and Rothenberg, M.E. (2003) Mast Cells Are Required for Experimental Oral Allergen-Induced Diarrhea. Journal of Clinical Investigation, 112, 1666-1677. http://dx.doi.org/10.1172/JCI19785

[23] Bland, J.M. and Altman, D.G. (2004) The Logrank Test. British Medical Journal, 328, 1073. http://dx.doi.org/10.1136/bmj.328.7447.1073

[24] Chehade, M. and Mayer, L. (2005) Oral Tolerance and Its Relation to Food Hypersensitivities. Journal of Allergy and Clinical Immunology, 115, 3-12. http://dx.doi.org/10.1016/j.jaci.2004.11.008

[25] Saito, S., Yoshida, M., Ichijo, M., Ishizaka, S. and Tsujii, T. (1993) Transforming Growth Factor-Beta (TGF- $\beta$ ) in Human Milk. Clinical \& Experimental Immunology, 94, 220-224. http://dx.doi.org/10.1111/j.1365-2249.1993.tb06004.x

[26] Ando, T., Hatsushika, K., Wako, M., Ohba, T., Koyama, K., Ohnuma, Y., Katoh, R., Ogawa, H., Okumura, K., Luo, J., Wyss-Coray, T. and Nakao, A. (2007) Orally Administered TGF- $\beta$ Is Biologically Active in the Intestinal Mucosa and Enhances Oral Tolerance. Journal of Allergy and Clinical Immunology, 120, 916-923. http://dx.doi.org/10.1016/j.jaci.2007.05.023

[27] Corthésy, B. (2007) Roundtrip Ticket for Secretory IgA: Role in Mucosal Homeostasis? Journal of Immunology, 178, 27-32. http://dx.doi.org/10.4049/jimmunol.178.1.27

[28] Duc, M., Johansen, F.E. and Corthésy, B. (2010) Antigen Binding to Secretory Immunoglobulin A Results in Decreased Sensitivity to Intestinal Proteases and Increased Binding to Cellular Fc Receptors. Journal of Biological Chemistry, 285, 953-960. http://dx.doi.org/10.1074/jbc.M109.059220 
[29] Grimshaw, K.E., Maskell, J., Oliver, E.M., Morris, R.C., Foote, K.D., Mills, E.N., Roberts, G. and Margetts, B.M. (2013) Introduction of Complementary Foods and the Relationship to Food Allergy. Pediatrics, 132, e1529-e1538. http://dx.doi.org/10.1542/peds.2012-3692

[30] Yoshida, M., Claypool, S.M., Wagner, J.S., Mizoguchi, E., Mizoguchi, A., Roopenian, D.C., Lencer, W.I. and Blumberg, R.S. (2004) Human Neonatal Fc Receptor Mediates Transport of IgG into Luminal Secretions for Delivery of Antigens to Mucosal Dendritic Cells. Immunity, 20, 769-783. http://dx.doi.org/10.1016/j.immuni.2004.05.007

[31] Nakata, K., Kobayashi, K., Ishikawa, Y., Yamamoto, M., Funada, Y., Kotani, Y., Blumberg, R.S., Karasuyama, H., Yoshida, M. and Nishimura, Y. (2010) The Transfer of Maternal Antigen-Specific IgG Regulates the Development of Allergic Airway Inflammation Early in Life in an FcRn-Dependent Manner. Biochemical and Biophysical Research Communications, 395, 238-243. http://dx.doi.org/10.1016/j.bbrc.2010.03.170

[32] Mosconi, E., Rekima, A., Seitz-Polski, B., Kanda, A., Fleury, S., Tissandie, E., Monteiro, R., Dombrowicz, D.D., Julia, V., Glaichenhaus, N. and Verhasselt, V. (2010) Breast Milk Immune Complexes Are Potent Inducers of Oral Tolerance in Neonates and Prevent Asthma Development. Mucosal Immunology, 3, 461-474. http://dx.doi.org/10.1038/mi.2010.23

[33] Burks, A.W., Laubach, S. and Jones, S.M. (2008) Oral Tolerance, Food Allergy, and Immunotherapy: Implications for Future Treatment. Journal of Allergy and Clinical Immunology, 121, 1344-1350. http://dx.doi.org/10.1016/j.jaci.2008.02.037 
Scientific Research Publishing (SCIRP) is one of the largest Open Access journal publishers. It is currently publishing more than 200 open access, online, peer-reviewed journals covering a wide range of academic disciplines. SCIRP serves the worldwide academic communities and contributes to the progress and application of science with its publication.

Other selected journals from SCIRP are listed as below. Submit your manuscript to us via either submit@scirp.org or Online Submission Portal.
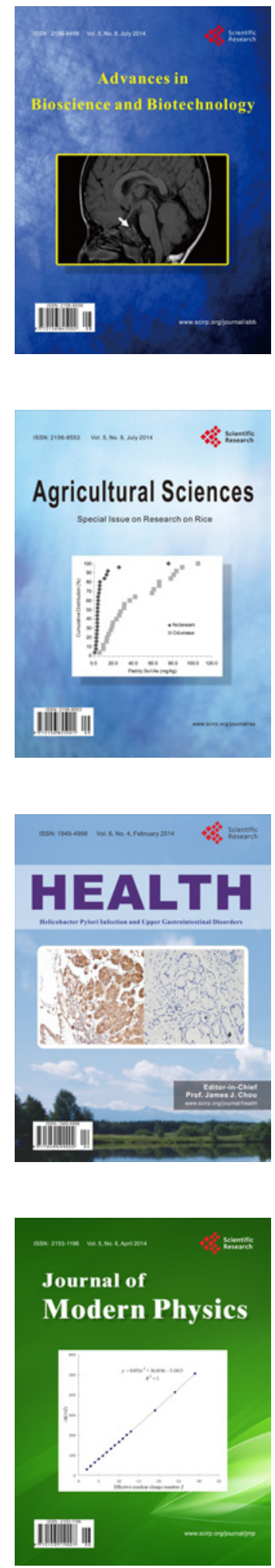
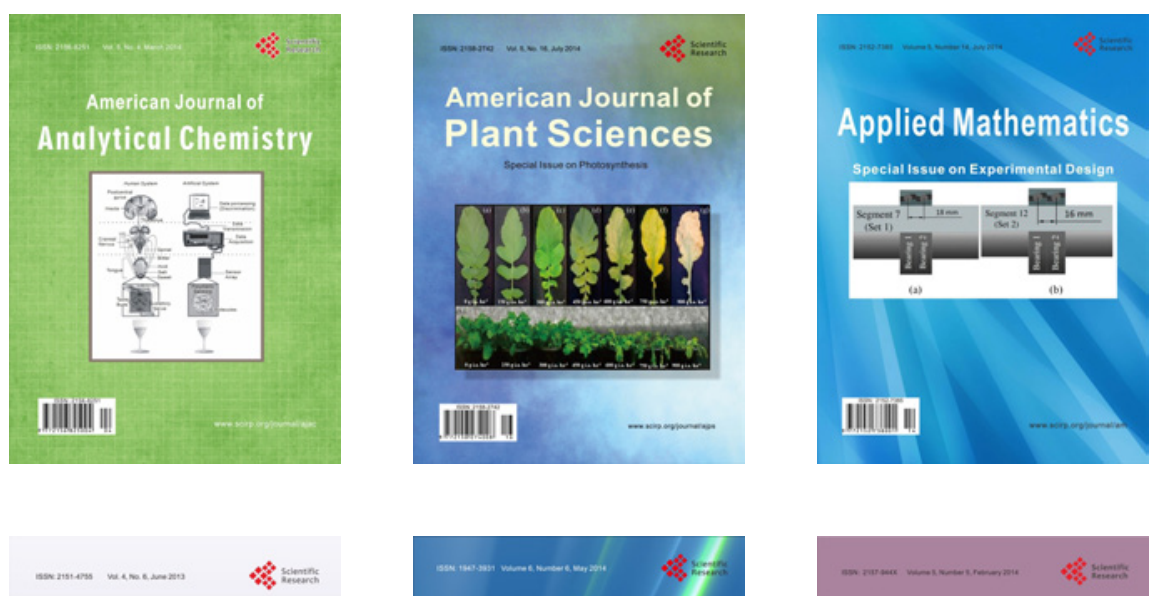

Creative Education
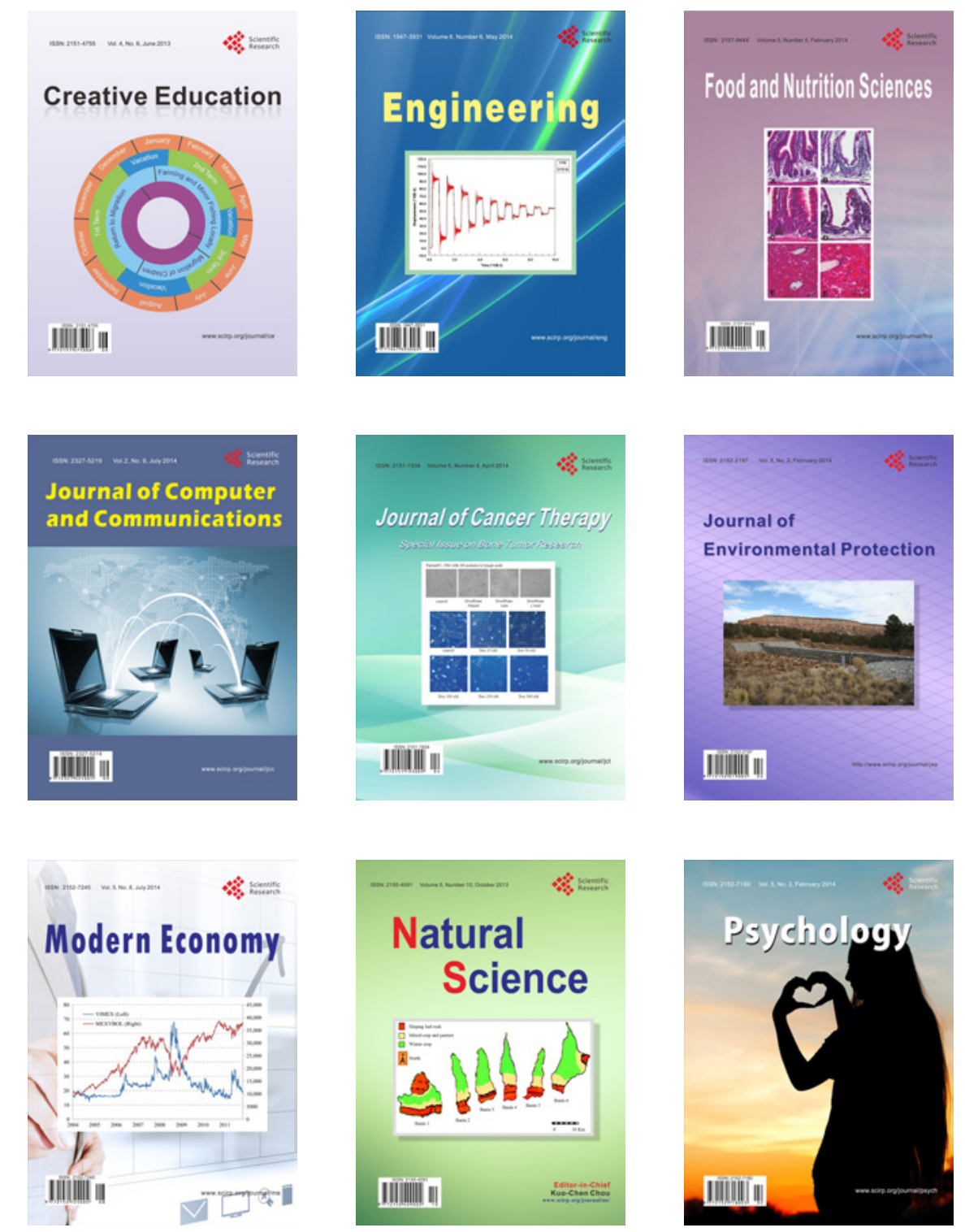